\title{
Management of distributed capacities in variable production networks
}

\author{
H.-P. Wiendahl, S. Lutz, K. Helms \\ Institute of Production Systems (IFA), University of Hanover \\ Callinstr. 36, 30167 Hannover, Germany \\ Tel: $++49 / 511 / 7623813$ \\ Fax: $++49 / 511 / 7623814$ \\ e-mail:lutz@ifa.uni-hannover.de
}

\begin{abstract}
Variable production networks offer new potentials to increase the capacity flexibility. This paper describes existing interfaces within such networks and explains how to exploit logistic potentials by subcontracting in networks. The paper's main focus is on the mechanisms and monitoring methods needed for subcontracting due to capacity problems.
\end{abstract}

\section{Keywords}

Production network, subcontracting, supply chain, throughput diagram

\section{INTRODUCTION}

Confronted with constant structural changes in society and the manufacturing industry, enterprises have undertaken several innovative activities for the optimisation of their processes. One approach enabling an extremely fast adaptation to quickly changing constraints involves building up a variable production network. This is a dynamic cooperation system or network of companies put in place for a limited period. As a part of a current research project on network-oriented production management, a number of theoretical methods from the fields of production planning and control, such as the funnel model, throughput diagrams and logistic operating curves, have been adopted for production management in a network of several partners (Wiendahl et. al., 1998). 


\section{VARIABLE PRODUCTION NETWORKS}

The trend for companies to focus on core competencies has forced enterprises to cooperate closely with their suppliers as well as with their customers in order to improve business performance. Originally, this led to the forming of supply chains, which are characterised rather by the share of information between suppliers and producers then between the suppliers themselves. In a continuation of this trend, production networks or supply nets have been created (Grandori and Soda, 1995; Nassimbeni, 1998), which are characterised by intensive communication between the participating companies even though they might represent the same level of value adding. That means, that in a production network the suppliers of a company should communicate with each other as well as with the company itself, leading to an intensive flow of information between all participants in a production network as depicted in Figure 1.

a) Supply Chain

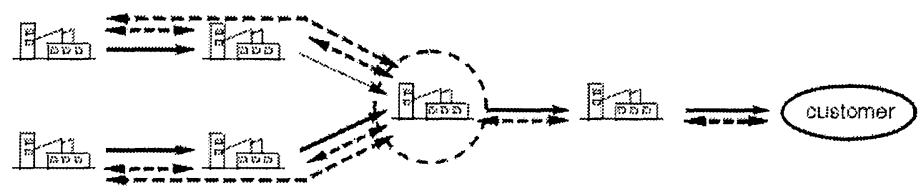

b) Production Network

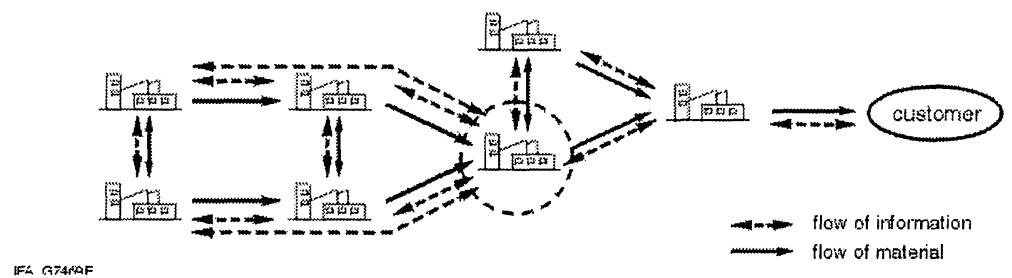

Figure 1 Supply chain and production network

This intensive flow of data helps the netpartners to plan more accurately and to adjust their capacities more effectively since information is provided both earlier and in more detail. Thus, production networks facilitate the avoidance of large deviations of demand along the value added chain as described by Forrester (1961).

\section{INTERFACES AND TYPES OF SUBCONTRACTING}

\subsection{Interfaces in a production network}

An important characteristic of production networks is that redundant resources are deliberately designed into their set-up and that redundancies are considered in production planning (Wiendahl and Helms, 1998). Thus, more than one partner is able to provide the same product or service within the network. The objective of providing redundant resources in a production network is to increase flexibility. 
The capability of companies to fulfil customer demands with respect to due dates is often constrained by a momentary limitation of capacity. When a lack of capacity occurs, companies usually try to exhaust internal potentials, e.g. by running extra shifts. However, the applicability of such measures is limited, therefore other methods of load adjustment need to be taken into consideration. An VDMA investigation revealed that at the moment $20 \%$ of production volume has been subcontracted mainly due to capacity problems (Leyendecker, 1999). Though, it is the aim of an production network to provide external resources within the network to the net partners by means of subcontracting. This increases the flexibility of companies to timely react to market demands. The most common types of subcontracting are described in the following.

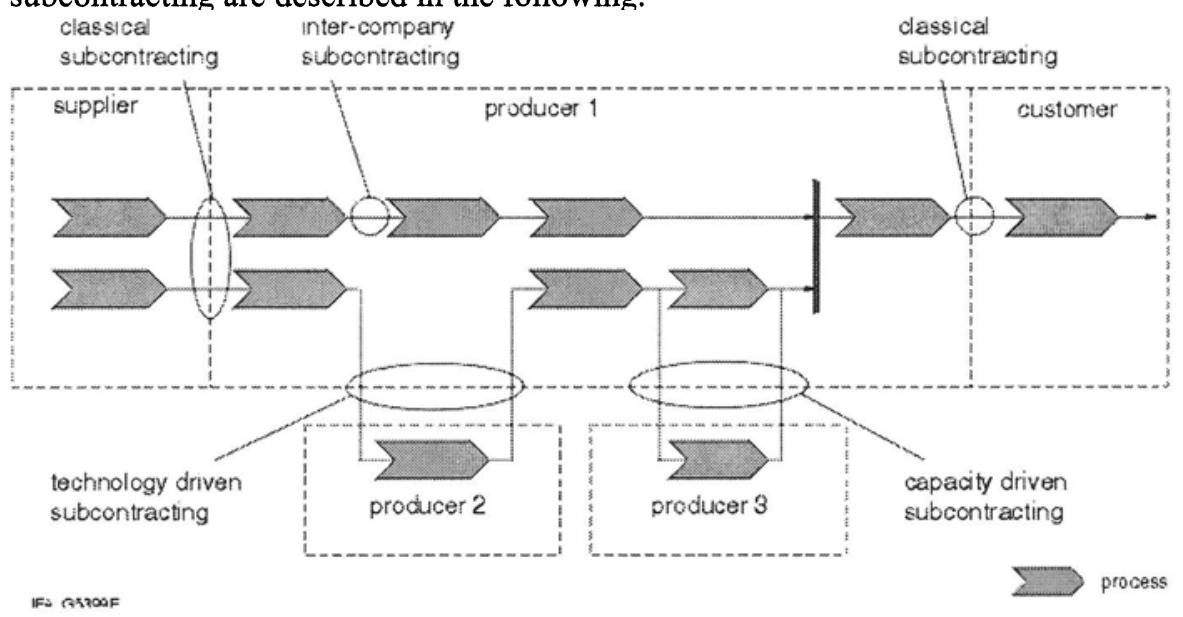

Figure 2 Network interfaces

As shown in Figure 2, the subcontracting function between supplier and producer may occur primarily in four different categories. The interfaces between the supplier and the producer or those between the producer and the customer can be described as classical subcontracting. The predominant contact between both partners is through the delivery of goods after a closed production process. Technology driven subcontracting describes the case of a company not conducting particular production operations itself. Thus, these operations need to be performed externally. One of the most important reasons for subcontracting is caused by capacity problems of the producer. In this case of capacity driven subcontracting, the producer assigns parts of his production to external manufacturers when a lack of capacity occurs. Capacity driven subcontracting has a highly short-term planning horizon and requires flexibility and a close cooperation with possible suppliers. A fourth type of subcontracting is the allocation of jobs between partially redundant factories of the same company, called inter-company subcontracting. The methods underlying the latter type of subcontracting are a combination of those of the former types. 
Redundancies increase the flexibility of the network considerably, but they also increase the need for coordination, since the planning of the dispersed resources requires a continuous and detailed flow of information between the partners. Accurate information is a prerequisite for the use of other netpartners' resources and for the allocation of orders to particular network partners according to their actual capability and performance. Therefore, for a successful exploitation of the inherent potential of a production network a monitoring tool that provides all netpartners with the required information is essential and needs to be employed.

Concentrating on the network interfaces and to meet the demands of a production network, the following requirements concerning a decentralised tool for supporting subcontracting need to be fulfilled (Wiendahl and Helms, 1998):

- The availability of resources and the status of orders should be monitored throughout the entire production network.

- The monitoring has to be applicable internally as well as between the partners.

- The different perspectives of the network partners (from the supplier to the producer and vice versa) need to be supported and if necessary data need to be capsuled.

Thus, a tool or a procedure is needed that supports and facilitates the identification of logistic bottlenecks and capacity problems.

In order to realise these requirements a software tool called FAST/net has been developed in an ongoing research project at the Institute of Production Systems (IFA) that employs basic methods of production logistics and provides procedures for the efficient use of redundancies in a network. The software tool provides detailed information of the status of orders and the availability of resources within the entire network.

\subsection{Capacity driven subcontracting}

Especially in the event of short-term peaks of demand, an internal increase of capacity is hardly possible. Hence, the use of external capacities in a production network allows a quick and responsive adjustment of capacities. The external capacity flexibility is achieved by subcontracting jobs to other partners in the network. This procedure is called capacity driven subcontracting and is facilitated by the developed software tool FAST/net.

The main aim of capacity driven subcontracting is the elimination of bottlenecks in the production. Therefore, the first step of capacity driven subcontracting is the identification of the production bottlenecks. Secondly, orders suitable for subcontracting are chosen. Finally, a simulation of the work system's logistic behaviour can be conducted, assuming that the jobs chosen are removed from the system and shifted to a netpartner.

The bottleneck analysis is based on the figure of the degree of demand. The degree of demand is a measure comparing the capacity needed in the future to the capacity available in the future and is expressed by the quotient of the planned input and the capacity. The software identifies bottlenecks by investigating the degree of demand and a worksystem's relative portion of the order lead time. For 
each of the critical work systems, those systems which degree of demand is more than $100 \%$ (hence, there is more capacity needed than available), a more thorough analysis with respect to the subcontracting-potential of the jobs at the system will be conducted. This is done by means of the throughput diagram which is generated by cumulating the work content of single jobs (in standard hours) in relation to their operation finish (Wiendahl, 1995). An example of a throughput diagram generated by the software tool is given in Figure 3.

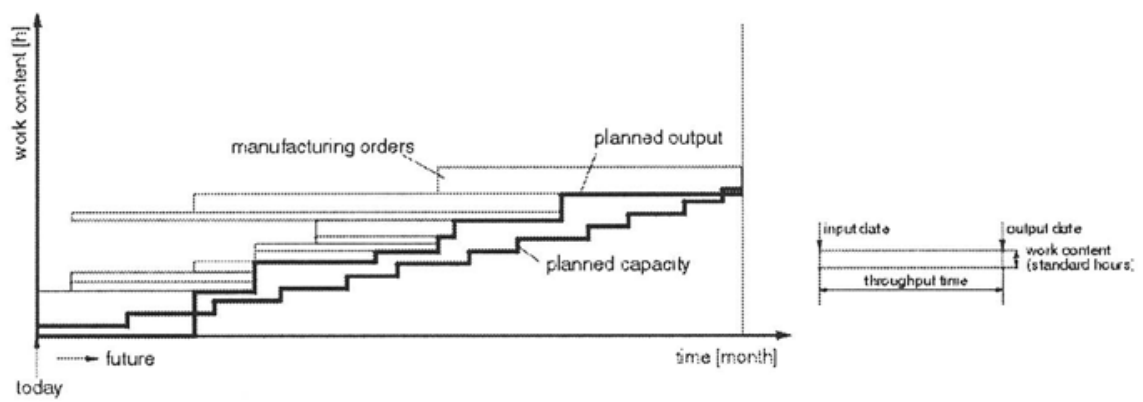

Figure 3 Throughput diagram of planned orders including subcontractable ones

The throughput diagram depicted in Figure 3 considers a future (planned input and output) perspective. The large horizontal distance between the planned output curve and the planned capacity curve indicates that the accuracy of delivery due date of orders planned in the future is at risk.

A rectangular throughput element represents a single job processed at the work system. The height of the throughput element indicates the work content in standard hours and the length describes the input and output dates in shop calendar days. It is a characteristic of bottleneck systems that the planned output curve lies above the capacity curve, meaning that in the future there are more jobs to be processed than the system is capable of. The difference between the planned output and the maximal possible output constrained by the capacity represents the work content which should be subcontracted.

In the next step, those orders which are chosen for subcontracting are marked in the throughput diagram. This can be done manually as well as automatically. The automatic choice is supported by the system under consideration of different aspects such as orders which have been subcontracted in the past, minimisation of production costs or reduction of throughput time.

The latter throughput oriented subcontracting aims to minimise throughput times of the internal production and the achievement of due dates by selecting those orders for subcontracting which would pass several bottleneck systems. Now, the orders chosen for subcontracting can be marked and a simulation of the expected harmonisation of the curves by excluding these orders can be conducted (Figure 4). 

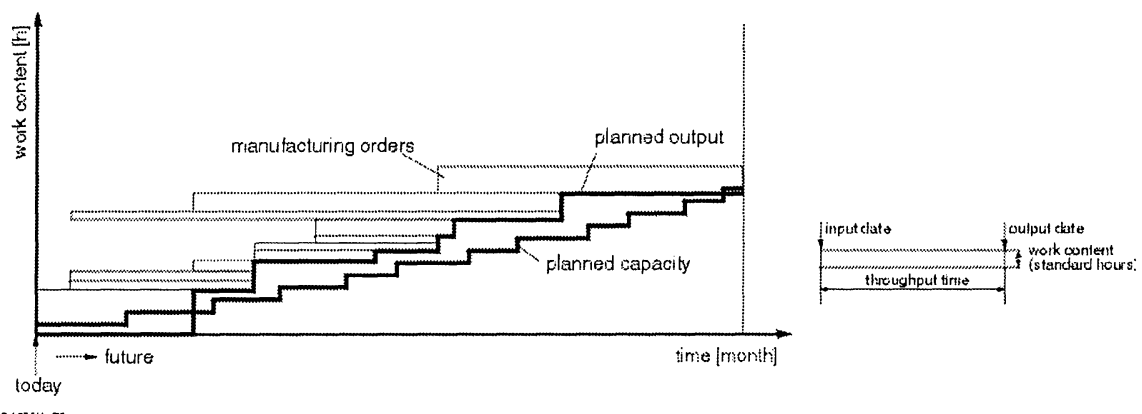

Figure 4 Throughput diagram of planned orders excluding subcontractable ones

This provides information about effects of possible subcontracting under consideration of the entire material flow. By this method, the interdependencies between the various work systems involved in the production process are not neglected and the emergence of work shortages due to delays at previous worksystems can be avoided at an expected bottleneck system.

Once the orders for subcontracting are finally marked and confirmed, these are booked into a separate subcontracting account which will be monitored by the supplier regularly.

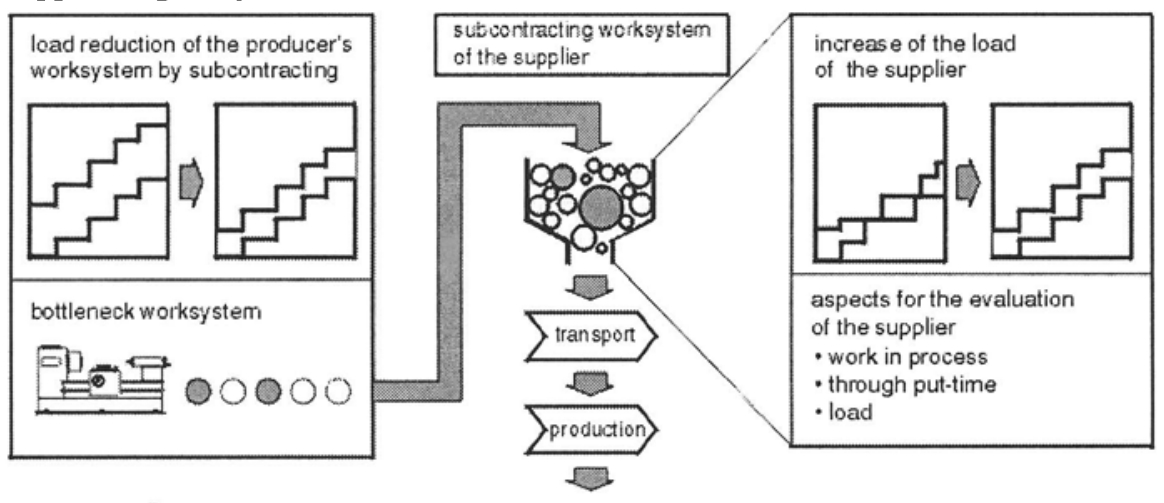

$$
\text { O subcontractable orders }
$$

Figure 5 Reduction of the load of the producer's worksystem by subcontracting

Subcontracting leads to an adjustment of the producer's as well as the supplier's load, as shown in Figure 5. The load of the producer's worksystem has been reduced and the load of the supplier's worksystem has been increased by shifting orders. 


\section{APPLICATIONS OF SUBCONTRACTING}

\subsection{An Example of the use of the subcontracting function}

The extent of and the way in which the software tool FAST/net or the subcontracting function are applied may vary depending on the company's demand. In the following, an example of an industrial application of the software tool is described.

Figure 6 depicts the application of capacity driven subcontracting by two companies linked by the software tool FAST/net. Company A produces machines and manufactures most of the components itself. In the event of a bottleneck that can be identified through FAST/net, company. A regularly subcontracts particular processes, e.g. drilling or milling, to an external manufacturer, company B. The PPC systems of both companies are connected with FAST/net, hence actual subcontracting data is processed by FAST/net. The companies have agreed to exchange data daily.

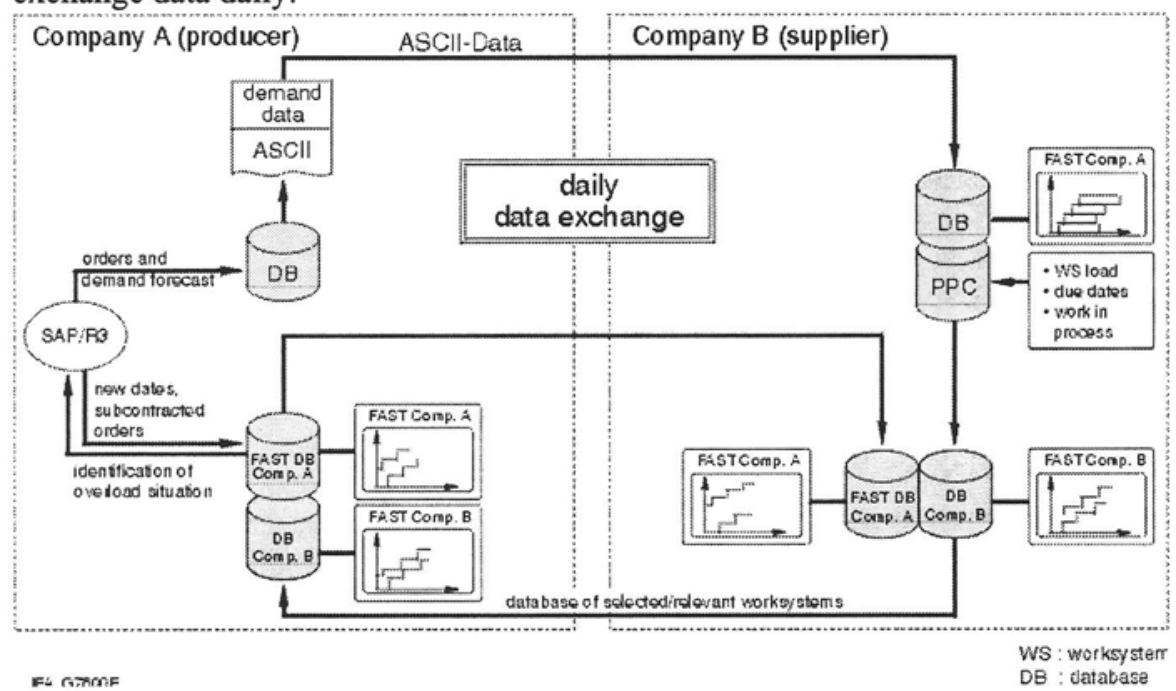

Figure 6 Application of the capacity driven subcontracting

In a first step, company A uses FAST/net for the identification of bottlenecksystems. The throughput diagrams of the critical worksystems provide detailed information of the actual situation. By means of the software tool, orders suitable for subcontracting are identified and the effects of their removal can be investigated, as described above. The information about those orders finally chosen for subcontracting is transferred to the PPC system of company A, in this case SAP $\mathrm{R} / 3$. The PPC system initiates a new scheduling run of the remaining orders and returns the resulting data to FAST/net. Furthermore, the PPC system generates orders which are transferred to the supplier, company B. These orders are put into a separate database at company B that is linked to company B's PPC System. The 
database, which represents the subcontracting account of company A, can be visualised in FAST/net. The subcontracting data from company A contains all relevant information for the planning and scheduling of the orders at the supplier. The subcontracted orders are scheduled in the PPC system of company B. The entire production of $\mathrm{B}$ is monitored by FAST/net, hence the load of all worksystems can be evaluated. From this data information about A's orders and agreed worksystems will be provided by means of a FAST/net database to the producer, company $\mathrm{A}$, by the subcontractor. Thus, the producer is able to monitor those worksystems of the supplier to which work is subcontracted. Additionally, the supplier is provided with the FAST/net database of those worksystems of the producer from which single orders are subcontracted. This allows the supplier to monitor the producer's actual load situation and to forecast the amount of work that may be subcontracted. Based on this information, the supplier may suggest orders for subcontracting or may adjust his own capacities to expected orders. On the other hand the producer can now evaluate the supplier by monitoring the supplier's worksystems and can allocate orders according to the supplier's actual capability. This increases the supplier's accuracy of planning and helps both partners to meet delivery times.

Thus, a more accurate scheduling and planning of loads and capacities can be achieved and both partners can react timely to changes in demand and anticipate future developments.

The two netpartners agreed that the producer, company A, provides the supplier with data about actual orders and forecasts of demand for the next six months. Furthermore, the supplier receives data describing the actual load situation at defined worksystems. On the other hand, the supplier allows the producer to monitor his capacities and provides data regarding the progress of the orders received from the producer.

The next steps of application will be that both parties communicate with each other directly via FAST/net. Also, a second supplier needs to be integrated into the net, so that communication between the suppliers can be realised.

\subsection{Constraints and Rules}

Although the technical realisation of subcontracting is enabled by above described software tool FAST/net, further aspects influencing the use of the subcontracting functions need to be taken into account.

One of the foremost prerequisites of the successful operating in a production network is the confidence between the partners involved. The information shared by the participants, e.g. the actual capacity utilisation of particular worksystems, has so far only been handled internally in most companies. In networks, this data is now made available to external netpartners. This leads to a new stage of confidence. Hence the netpartner have to agree in advance which data should be exchanged and how this data may be handled. Agreements have to be reached which guarantee that no confidential information is passed on to competitors. Alternatively, the data that should be exchanged can be filtered depending on the need of information and the intensity of the integration into the net. In this case, 
only preagreed data is exchanged and the company has complete control over its own data.

Furthermore, legal aspects have to be considered, too. This concerns mainly the liability of information and who is responsible for the provision and accuracy of the exchanged data. In particular, the intervals of data exchange need to be agreed.

\section{CONCLUSION AND OUTLOOK}

The formation of variable production networks is one approach for solving the problems caused by the increasing complexity of manufacturing in a turbulent environment. Variable production networks offer potentials for small and mediumsized enterprises to become efficient and competitive. Information and communication technology enables partnerships to work together much more closely and helps to adjust capacities, loads and utilisation by means of subcontracting.

This paper describes how capacity flexibility can be easily increased within a supply net if netpartners work closely together. Therefore, the existence of communication channels between netpartners is a definite prerequisite. In particular, the allocation of orders to subcontractors within a production network is one of the main methods for short-term modifications of capacities. This paper presents tools for the identification of bottlenecks in the production and methods supporting the decision whether particular orders should be subcontracted. They represent an easy to handle approach for the management of production networks and for the scheduling and allocation of orders within a production network along the supply chain.

Further research will be carried out to develop concepts and criteria for the choice of orders for subcontracting and the evaluation of the effects of subcontracting on the flow of orders through a production. Additionally, the joint monitoring of netpartner stocks should also be integrated in the software tool.

\section{REFERENCES}

Forrester, J. W. (1961) Industrial Dynamics, John Wiley \& Sons, New York.

Grandori, A. and Soda, G. (1995) Inter-firm Networks: Antecedents, Mechanisms and Forms. Organization Studies, 16, 183-214.

Leyendecker, (1999) VDMA Studie zur Fertigung im Maschinenbau 1998, VDMA, Frankfurt a.M.

Nassimbeni, G. (1998) Network structures and co-ordination mechanisms - A Taxonomy. International Journal of Operations \& Production Management, $18,538-554$.

Wiendahl, H.-P. (1995) Load-oriented Manufacturing Control, Springer, New York. 
Wiendahl, H.-P. and Helms, K. (1998) Successful Operating in an 'Alliance of the Best', in Organizing the Extended Enterprise (ed. P. Schönsleben, A. Büchel ), Chapman \& Hall, London.

Wiendahl, H.-P., Helms, K., Höbig, M. and Leistner, H. (1998) Fremdvergabe in Produktions-Netzwerken. Industrie Management, 14, 39 - 43.

\section{BIOGRAPHY}

Prof. Dr.-Ing. Dr.-Ing. E.h. Hans-Peter Wiendahl, born in 1938, studied Mechanical Engineering at the University of Aachen where he gained his doctorate in 1970. From 1972 to 1974 he was head of "Planning and Quality" at an industrial firm and continued as head of the Technical Department until 1979, when he was appointed full-time professor and director of the Institute of Production Systems (IFA) at the University of Hanover. He has been a full member of CIRP since 1989. In 1997 he became President of the German Scientific Society of Production Engineering (WGP).

Dipl.-Ing. Stefan Lutz, born in 1972, studied Manufacturing Engineering and Law at the Universities of Bremen and Hannover. He graduated in 1998. As part of his degree, he spent six months at the University of Strathclyde in Glasgow where he worked on performance measurement. At present he is a research assistant at the Institute of Production Systems (IFA) and project manager of the industrial research project "Networkable Production Management".

Dipl.-Ing. Katja Helms, born in 1969, studied Manufacturing Engineering at the University of Hannover. As part of her degree, she spent one semester at the Massachusetts Institute of Technology (MIT). Since June 1995, she has worked as a research assistant at the Institute of Production Systems (IFA) in Hannover in the department of Production Management. 